\title{
Psychiatric expert evidence and the new partial defences of diminished responsibility and loss of control
}

\author{
Rajan Nathan \& Simon Medland
}

\begin{abstract}
SUMMARY
Psychiatric expert witnesses instructed to undertake assessments of defendants charged with murder should be familiar with the partial defences of diminished responsibility and loss of control. The Coroners and Justice Act 2009 enacted major amendments to the partial defence of diminished responsibility and introduced a new defence of loss of control to replace the provocation partial defence. In this article, the changes to the law are described with particular focus on the implications for the psychiatric assessment.
\end{abstract}

\section{LEARNING OBJECTIVES}

- Understand the implications of the enactment of the Coroners and Justice Act 2009 for psychiatric experts in homicide cases

- Develop a framework of assessment for defendants charged with murder to inform one's expert opinion relevant to diminished responsibility and loss of control

- Appreciate the responsibilities of providing expert testimony in homicide cases

\section{DECLARATION OF INTEREST}

None

Diminished responsibility and loss of control are partial defences to the offence of murder (hereafter 'defences' for the sake of simplicity). They are partial defences because they reduce the offence of murder to manslaughter; they do not result, as successful defences such as self-defence do, in acquittal. Psychiatric evidence is crucial for the defence of diminished responsibility and is sometimes admitted in relation to loss of control. While psychiatric experts must first and foremost ground their evidence in their area of psychiatric expertise, the psychiatrist should also have a sufficient grasp of the relevant legal issues to frame findings in a way that assists the court in its deliberations. The Coroners and Justice Act 2009 introduced, for England, Wales and Northern Ireland, changes to the law on diminished responsibility and replaced the previous defence of provocation with a new defence of loss of control. ${ }^{a}$ In this article, the implications of the new provisions for the psychiatric expert witness are explored.

\section{Background}

\section{Murder}

The crime of murder 'is committed where a person of sound mind and discretion unlawfully kills any reasonable creature in being and under the Queen's peace with intent to kill or cause grievous bodily harm' (Archbold 2015: 19-1). However, if the accused suffered diminished responsibility or a loss of self-control, the offence is reduced to manslaughter. Whereas a murder conviction attracts a mandatory life sentence, the sentence for manslaughter is at the judge's discretion. For diminished responsibility, it is for the defence to raise the issue on the factual evidence and make the case on the balance of probabilities ("more likely than not'). In relation to loss of control, if the judge decides there is sufficient evidence that there might have been loss of control, it is for the prosecution to disprove loss of control beyond any reasonable doubt.

\section{Diminished responsibility}

Diminished responsibility was introduced into English law by the Homicide Act 1957, although the doctrine had been known in the Scottish courts since the 19th century, if not earlier, and the term was first used in 1939 (Kirkwood v HM Advocate 1939). However, the 1957 definition (which we will call the 'old DR') (Box 1) came to be considered outdated in light of developments in psychiatric practice (Law Commission 2004, 2006). In particular, the term 'abnormality of mind' and the specified causes in parentheses were considered not to reflect medical understanding of psychiatric disorder. Moreover, for the defence to succeed, the Act required that the effect of the abnormality of mind was to substantially impair mental responsibility. The concept of responsibility, which has a moral element, is not amenable to
Rajan Nathan is a consultant forensic psychiatrist with Cheshire and Wirral Partnership NHS Foundation Trust, an Honorary Senior Research Fellow at the University of Liverpool and a Visiting Professor at the University of Chester. As a consultant forensic psychiatrist, he has been involved in the delivery, development and overseeing of mental health services within secure settings, and of specialist personality disorder services in health and criminal justice settings. His academic interests lie in the fields of serious violence and personality disorder. He has delivered expert evidence in a wide range of legal cases, including many murder trials. Simon Medland was called to Bar by Middle Temple in 1991 (Gottlieb Award and Ede \& Ravenscroft Prize). He took Silk in 2011. He was appointed a Crown Court Recorder in 2005 and he is authorised to hear Class 2 (serious sexual offence) cases. His practice is in criminal law and inquests. He has cross-examined Professor Nathan on a number of occasions, which have been memorable for both parties concerned. Correspondence Professor Rajan Nathan, Saddlebridge Recovery Centre, Chelford Road, Nether Alderley SK10 4UJ, UK. E-mail: r.nathan@liv.ac.uk

a. In Scotland, the common law defence of diminished responsibility was abolished by the amendments to the Criminal Procedure (Scotland) Act 1995 made by the Criminal Justice and Licensing (Scotland) Act 2010 (Thompson 2014). In Ireland, the defence was rejected in the Irish Supreme Court but is now recognised under the Criminal Law (Insanity) Act 2006 (Rix 2011). 
BOX 1 The 'old' and 'new' definitions of diminished responsibility

The 'old DR': section 2(1) of the Homicide Act 1957 'Where a person kills or is party to the killing of another, he shall not be convicted of murder if he was suffering from such abnormality of mind (whether arising from a condition of arrested or retarded development of mind or any inherent causes or induced by disease or injury) as substantially impaired his mental responsibility for his acts and omissions in doing or being a party to the killing.'

The 'new DR': section 52(1) (England and Wales), and section 53(1) (Northern Ireland), of the Coroners and Justice Act 2009

'A person ("D") who kills or is party to the killing of another is not to be convicted of murder if $D$ was suffering from an abnormality of mental functioning which-

(a) arose from a recognised medical condition,

(b) substantially impaired D's ability to do one or more of the things mentioned in subsection $(1 \mathrm{~A})$, and

(c) provides an explanation for D's acts and omissions in doing or being a party to the killing.'

Note: subsections (1A) and (1B) are set out in Box 3 .

evidence-based testing within the psychiatric method. Therefore, the specific issue of whether an individual's mental responsibility is impaired should remain a matter for the court rather than the psychiatrist.

A new definition to replace section 2 of the Homicide Act 1957 was introduced by the Coroners and Justice Act 2009 (the 'new DR') (Box 1). 'Abnormality of mental functioning', which engenders notions of internal processes and faculties, replaces the previous term 'abnormality of mind'. The legal definition of abnormality of mind (Box 2) remains relevant as 'things' listed in the 'new DR' (Box 3) can be traced to this judgment. Within the 'new DR', there is no longer a concern with specific aetiological categories. The requirement of this

BOX 2 Judicial definition of 'abnormality of mind'

'[... ] a state of mind so different from that of ordinary human beings that the reasonable man would term it abnormal. It appears to us to be wide enough to cover the mind's activities in all its aspects, not only the perception of physical acts and matters, and the ability to form a rational judgment as to whether an act is right or wrong, but also the ability to exercise willpower to control physical acts in accordance with that rational judgment'

$R v$ Byrne [1960]
BOX 3 Impairment of abilities: Coroners and Justice Act 2009

Subsections (1A) and (1B) below clarify section 52(1)/53(1) of the 'new $D R^{\prime}$ (Box 1)

Section 52(1A) (England and Wales) and 53(1A) (Northern Ireland)

'Those things are-

(a) to understand the nature of D's conduct;

(b) to form a rational judgment;

(c) to exercise self-control.'

Section 52(1B) (England and Wales) and 53(1B) (Northern Ireland)

'For the purposes of subsection (1)(c), an abnormality of mental functioning provides an explanation for D's conduct if it causes, or is a significant contributory factor in causing, D to carry out that conduct.'

defence, that the abnormality of mental functioning arose from a 'recognised medical condition', makes the need to refer to accepted diagnostic conventions (most notably DSM-5 and ICD-10) more explicit.

The effect of the abnormality must be to substantially impair one of three defined specific abilities (rather than the defendant's mental responsibility) (Box 3). Abnormal mental functioning provides an explanation for the defendant's involvement in the killing if it causes or is a significant contributory factor in causing the defendant's behaviour (Box 3), rather than, as previously, the defendant's mental responsibility.

These provisions came into effect on 4 October 2010 and only apply to acts or omissions that occurred on or after that date. If the killing occurred before that date, then the unamended provisions of section 2 of the Homicide Act will continue to apply.

\section{Provocation and loss of control}

The forerunner of loss of control was provocation, which was codified by section 3 of the Homicide Act 1957 (Box 4). This defence, which was a mixture of common law and statute, was not based on a clear rationale, and ambiguity arose from differing judicial interpretations (Law Commission 2004, 2006). The Coroners and Justice Act 2009 abolished the common law defence of provocation and repealed section 3 of the Homicide Act 1957. In its place, the Coroners and Justice Act introduced a new defence to murder, i.e. loss of control (Box 4).

The first element of this defence is whether the defendant's acts at the time of the incident were a result of their 'loss of self-control'. In contrast to the former defence of provocation, the Coroners and Justice Act removes the requirement that the loss of 
BOX 4 The defences of provocation and loss of control

The old defence of provocation: section 3 of the Homicide Act 1957

'Where on a charge of murder there is evidence on which the jury can find that the person charged was provoked (whether by things done or by things said or by both together) to lose his self-control, the question whether the provocation was enough to make a reasonable man do as he did shall be left to be determined by the jury, and in determining that question the jury shall take into account everything both done and said according to the effect which, in their opinion, it would have on a reasonable man.'

The new defence of loss of control: section 54(1) of the Coroners and Justice Act 2009

'Where a person ("D") kills or is a party to the killing of another (" $\mathrm{V}$ "), $\mathrm{D}$ is not to be convicted of murder if-

(a) D's acts and omissions in doing or being a party to the killing resulted from D's loss of self-control,

(b) the loss of self-control had a qualifying trigger, and

(c) a person of D's sex and age, with a normal degree of tolerance and self-restraint and in the circumstances of $D$, might have reacted in the same or in a similar way to $\mathrm{D}$.'

self-control was sudden (section 54(2), Box 5). This introduces the potential for the plea to be advanced where there has been a 'cumulative impact' of the provocation over a period of time, which may be the case in domestic violence. The second element is that there was a qualifying trigger for the loss of self-control, which is specified as the defendant's fear of serious violence or a justifiable sense of being seriously wronged due to extremely grave words or actions (section 55(4), Box 5). However, the defence is not available if the defendant incited the provoking words or actions to create an excuse for the violence (section 55(6), Box 5). The third element of the loss of control defence is whether a hypothetical individual of the same age and gender as the defendant, with an ordinary level of tolerance and self-restraint might, in the circumstances of the defendant, have reacted in the same way. Circumstances that are relevant only because they have a bearing on tolerance and self-restraint are excluded (section 54(3), Box 5). The plea is not available to defendants who killed in an act of revenge (section 54(3), Box 5).

\section{Roles and responsibilities of the psychiatric expert witness}

For a comprehensive description of the roles and responsibilities of the psychiatric expert witness,
BOX 5 Clarifications of loss of control: Coroners and Justice Act 2009

These sections clarify section 54(1) (referred
to as subsection 1) of the loss of control
defence (Box 4)
defence (Box 4)

\section{Section $54(2)$}

'For the purposes of subsection (1)(a), it does not matter whether or not the loss of control was sudden.'

\section{Section 54(3)}

'In subsection (1)(c), the reference to "the circumstances of $D$ " is a reference to all of D's circumstances other than those whose only relevance to D's conduct is that they bear on D's general capacity for tolerance or self-restraint.'

\section{Section 54(4)}

'Subsection (1) does not apply if, in doing or being a party to the killing, $\mathrm{D}$ acted in a considered desire for revenge.'

\section{Section 55(3)}

'This subsection applies if D's loss of self-control was attributable to D's fear of serious violence from $V$ against $D$ or another identified person.'

\section{Section 55(4)}

'This subsection applies if D's loss of selfcontrol was attributable to a thing or things done or said (or both) which-

(a) constituted circumstances of an extremely grave character, and

(b) caused D to have a justifiable sense of being seriously wronged.'

\section{Section 55(6)}

'In determining whether a loss of self-

(a) D's fear of serious violence is to be disregarded to the extent that it was caused by a thing which $D$ incited to be done or said for the purpose of providing an excuse to use violence;

(b) a sense of being seriously wronged by a thing done or said is not justifiable if $D$ incited the thing to be done or said for the purpose of providing an excuse to use violence;

(c) the fact that a thing done or said constituted sexual infidelity is to be disregarded.' control had a qualifying trigger-

the reader is encouraged to refer to other sources (e.g. Rix 2008, 2011). In brief, expert witnesses differ from other witnesses in that they are able to offer opinion evidence. This evidence may be introduced where the matter before the court is likely to be outside the knowledge and experience of a lay person (i.e. a member of the jury). The expert witness has an overriding duty to provide impartial evidence and not to mislead the court. In addition, as emphasised by the Law Commission (2011), there should be 'evidentiary reliability', which will be tested by factors such as the extent and quality of the data on which the opinion is based, the safety of any inference, the accuracy and reliability of test results, the evidence base for material relied upon, the extent to which opinion is based on material outside the expert's expertise, the completeness of the available information, explanation of the expert's preference if there is a range of opinion, and whether the expert's methods follow established practice (Criminal Practice Directions 2014). This should not cause difficulties when presenting an opinion about psychopathology or diagnosis, as long as the psychiatrist adheres to recognised assessment approaches, symptom definitions and diagnostic algorithms. However, often (including in the case of diminished responsibility and loss of control) psychiatric evidence is sought to 
assist the court in relation to mental processes. The psychiatric expert needs to ensure that their opinion, which will be taken by the court to be authoritative, is based on sound methodology and a valid evidence base. Although there is clinical and scientific literature relevant to mental processes, it is not collated in easily accessible sources in the way that psychiatric texts and diagnostic manuals provide a valid point of reference for opinions on psychopathology and diagnosis.

\section{Psychiatric evidence and diminished responsibility}

\section{The psychiatric examination and opinion}

The psychiatrist assessing a defendant in a case where diminished responsibility has been raised should consider four questions (Box 6).

First, the psychiatric assessment should inform an opinion on whether the defendant was suffering from a psychiatric disorder at the time of the killing. The introduction of the phrase 'recognised medical condition' requires the psychiatrist to adhere to 'recognised' approaches to diagnosis. This is likely to mean making reference to either ICD or DSM. However, there may be circumstances in which it is appropriate to refer to some other recognised or authoritative approach to psychiatric diagnosis or the classification of psychiatric disorder.

Second, diminished responsibility requires that there was an 'abnormality of mental functioning' arising from the 'recognised medical condition'. Until 'abnormality of mental functioning' acquires a judicial definition, interpretation of the term is likely to be influenced by the 'abnormality of mind' test as set out in $R_{v}$ Byrne [1960] (Box 2). However, it is not a term that has an agreed meaning within psychiatric practice. As highlighted above, experts should confine their opinions to their area of expertise, and therefore caution should be exercised in offering evidence on the presence of an issue for which there is not an agreed clinical definition. A widely used clinical construct that refers to mental functioning at a particular time is 'mental state'. Therefore, in examining, and offering an opinion on, whether the defendant's state of mind was disturbed, and whether this disturbance would be considered by a jury to amount to an abnormality of mental functioning according to the Coroners and Justice Act 2009, the psychiatrist may adopt the conventions of mental state examination and mental state abnormalities. Thus, if the psychiatric evidence indicates that the defendant has a verified diagnosis of schizophrenia, but there was no appreciable mental state disturbance due to the schizophrenia at the time of the incident, then this is unlikely to support diminished responsibility.
BOX 6 Issues to be addressed by the psychiatric examination in relation to diminished responsibility

1 Presence of psychiatric disorder

- Was there a recognised medical condition at the time of the incident?

- If so, specify with reference to recognised diagnostic terms (e.g. ICD or DSM) and set out diagnostic criteria.

2 Presence of abnormality of mental functioning

- At the material time, was there an abnormality of mental functioning that arose from the recognised medical condition?

- If so, describe using accepted terms and definitions.

3 Effect of abnormality of mental functioning

- Did the abnormality of mental functioning (that arose from the medical condition) substantially impair the individual's ability to understand the nature of his/her actions, to form a rational judgement or to exercise self-control?

- If so, describe how (on the basis of relevant recognised mental processes) and, if possible, estimate the extent of the impairment.

4 Connection between abnormality of mental functioning and behaviour

- Did the abnormality of mental functioning cause, or make a significant contribution to, the defendant's acts or omissions in being a party to the killing?

- If so, describe the nature and extent of the connection (on the basis of relevant recognised mental processes) so as to provide an explanation for the defendant's acts or omissions in being a party to the killing.

Third, the definition of diminished responsibility additionally requires examination of the effect of any identified abnormality of mental functioning (arising from a recognised medical condition) on the three specified mental processes. These are to understand the nature of the defendant's conduct, to form a rational judgement and to exercise selfcontrol, and they are examined further in the next section.

Fourth, whether the abnormality 'provides an explanation' for the defendant's involvement in the killing (i.e. it causes or is a significant contributory factor in causing the defendant to display that conduct) needs to be considered. Thus, the psychiatrist should explore and, if possible, offer an opinion on, the connection between the mental state abnormality and the defendant's behaviour at the time of the killing.

In framing their opinion, the psychiatrist needs to remember that the questions posed by this partial defence are matters of fact that are entirely within the jury's province. Psychiatric evidence may be influential, but it is not determinative. 


\section{Specified mental processes}

The psychiatrist's expert opinion on whether there is substantial impairment of one of the mental processes should be informed by an understanding of the relevant psychiatric evidence base. Although there is not a coherent body of evidence for each of the processes, it is possible to consider whether any identified mental state abnormalities are recognised to cause impairment in one or more of the processes. There is a tension for the psychiatric expert. On the one hand, the psychiatric expert should not generate their own interpretation of a term. On the other hand, the psychiatrist has to come to a view about the meaning of the term to be able to assist the court in addressing whether there is impairment. Case law, arising from the testing of decisions made in courts where the case is first heard ('courts of first instance') in higher courts through the appeal process, is often a useful resource to inform the expert's understanding of legal terms. While this resource is available for more mature defences, such as insanity or the 'old DR', there has so far been no need for the Court of Appeal to conduct legal analysis of the terms used in the 'new DR'.

The similarities between the wording of section 52(1A) of the Coroners and Justice Act 2009 (Box 3) and the first limb of the M'Naghten rules have been noted (Mackay 2010). However, whereas for insanity it must be clearly proven that the defendant 'did not know the nature and quality of the act he was doing', the Coroners and Justice Act appears to set a lower threshold by reference to impairment as opposed to the absence of understanding. A distinction may also be made between the mental processes suggested by the wording ('know' versus 'understand') of the respective defences. 'To know' means to be aware, and it is not difficult to imagine mental state abnormalities that may result in the individual not being aware of the nature or quality of what they were doing. 'To understand' suggests interpretation or perception of meaning. The concept of interpreting or perceiving the meaning of one's own behaviour is not an easy one to grasp. However, the psychiatrist's examination, and opinion, should focus on the individual's thoughts about what they were doing and about the consequences of their actions and how any mental state abnormality may have influenced their train of thinking. In exploring the notion of the person's ability 'to understand the nature of [their] conduct', the Law Commission presented the hypothetical case of a 10-year-old boy who had played violent video games excessively and did not have an understanding that a person whom they killed could not be revived in the way that occurred in the games (Law Commission 2006). This is an example of a serious impairment in the individual's capacity to understand the consequences of their actions arising from a distorted view about the effects of violent attack.

Three examples of substantial impairment of the capacity to 'form rational judgement' are presented in the Law Commission report (Law Commission 2006). First, a woman suffering from post-traumatic stress disorder due to her husband's violent abuse comes to believe that she can only rid the world of his sins by burning him to death. Second, a depressed man who kills his wife at her request says that he had found it increasingly difficult to stop her requests dominating his thoughts to the exclusion of all else and he thought he would never think straight again until he had acceded to her request. These examples illustrate how the irrational judgement may be the motivating factor for a killing. Third, a 'mentally sub-normal' boy who takes part in a killing under his brother's instructions discloses that he would not dream of disobeying his brother and cannot contemplate that his brother would tell him to do something if it was really wrong, even if it involves killing. In this case, it would appear that the irrational judgement (about right and wrong) arises as a consequence of a vulnerability to the malign influence of a dominant figure.

The Law Commission's example of substantial impairment of the capacity to 'control him or herself' seems to include irrational judgement as well as impaired self-control (Law Commission 2006). This is the case of a man who says that sometimes the devil takes control of him and implants in him a desire to kill that must be acted upon before the devil will go away.

The phrase 'substantially impaired', which has been retained in the 'new DR', has been subjected to legal analysis. It was held in $R v_{v}$ Golds [2014], if clarification of the term 'substantial' is necessary, then the jury should be advised that if they consider that the impairment did not make any great difference, they would find the defendant guilty of murder (Box 7). In order to assist the court to address whether the abnormality of mental functioning substantially impaired one or more of the three mental abilities, the psychiatrist should endeavour to quantify the effect of the mental state disturbance, although it must be acknowledged that this is not an objective method of quantification.

\section{Mental state abnormalities and diminished responsibility}

To demonstrate the issues relevant to diminished responsibility that may be associated with 
BOX 7 Judicial definition of 'substantially impaired'

In $R v$ Golds [2014], the appellant subjected his partner to a fatal knife attack. He had a history of mental illness and was being treated for psychosis and depression. He disclosed that in the period before the killing he had stopped taking prescribed medication for his psychiatric condition. In spite of supporting expert psychiatric and psychological evidence, the defence of diminished responsibility did not succeed.

One of the grounds of appeal was that the judge had wrongly refused to direct as to the meaning of 'substantial', with the effect, it was submitted, that the jury adopted a more stringent standard than they ought.

In dismissing the appeal, it was held that judges should refuse to further explain the term 'substantial' as the meaning is obvious. However, if jurors requested further assistance they should be directed to the narrower meaning offered in $R v$ Simcox [1964]: 'Do we think, looking at it broadly as common-sense people, there was a substantial impairment of his mental responsibility in what he did? If the answer is "no", there may be some impairment, but we do not think it was substantial, we do not think it was something that really made any great difference, although it may have made it harder to control himself, to refrain from crime, then you would find him guilty'.

different types of mental state abnormalities, two hypothetical case examples are used here. No assumption is being made about whether a defence in such cases would succeed.

\section{Schizophrenia spectrum disorders}

Case: A male, who had a previously recorded diagnosis of schizophrenia, attacked and fatally wounded a stranger and disclosed to a number of witnesses and to the psychiatrist that he believed that there was a conspiracy to kill him and that he heard voices telling him that the victim was part of this conspiracy.

To be able to assist the court on the matter of whether there is a recognised medical condition, the psychiatrist will need to come to a view on whether the generally accepted criteria for a diagnosis of schizophrenia were satisfied at the time of the killing. The examination should consider the potential for co-occurring conditions which, if present, should be presented with reference to generally accepted diagnostic criteria. The psychiatrist should also consider whether the conspiratorial beliefs and voices represent recognised types of psychopathology (e.g. delusions and hallucinations) according to accepted definitions. If, in the view of the psychiatrist, the clinical data support a diagnosis of schizophrenia (i.e. a recognised medical condition) and the presence of delusions and hallucinations (recognised types of mental state abnormality), an opinion should also be offered on the link between the diagnosis and the psychopathology. Assuming that there is no co-occuring condition and no substances had been taken, it is likely to be uncontroversial that the identified delusions and hallucinations were a manifestation of the diagnosed condition. The psychiatric assessment should additionally address the impact of the mental state abnormalities on mental functioning, with particular reference to the effect on the patient's understanding of his behaviour, on his rational judgement and on his self-control.

In practice, cases are rarely as clear cut as this. Although there may be evidence of psychotic symptoms before and after the offence, if the defendant does not have a clear recollection of the incident and their motives, and there are no other witnesses to fact, it can be difficult for the expert to come to a definitive view on whether, and in what way, the symptoms influenced behaviour. This does not preclude the expert from offering a view, but the rationale for the opinion and caveats regarding the limitations of the basis of the opinion should be presented. It is not uncommon for the defendant in such cases to be intoxicated. The court may wish to determine the relative contributions of the intoxication and of the psychotic symptoms to the defendant's behaviour. Current psychiatric understanding of mental functioning does not support such an approach. In reality, there is a likely to be a complex interaction between the intoxication and the psychosis that influences behaviour in various ways. Therefore, any opinion about the extent of the contribution of differing factors should be presented with caution.

\section{Personality disorders}

Case: A woman, with a long history of changeable moods and repeated self-laceration, who had been in a discordant relationship with her partner, confronted him on hearing a rumour that he was planning to leave her. There was a volatile exchange and, when her partner made to leave the property, she took a knife from her kitchen and fatally stabbed him.

The question of whether there is a diagnosis of personality disorder (or any diagnosable condition) should be addressed in accordance with diagnostic rules. If there is evidence in favour of a diagnosis of borderline personality disorder, consideration will need to be given to whether any identified mental state disturbance at the time of the killing is related to the personality disorder. For example, a spontaneous account consistent with features of 
borderline personality disorder (e.g. a profound change of self-image and affect and a degree of dissociation at the prospect of anticipated abandonment) would support a link, particularly if there was evidence of previous tendencies towards abandonment avoidance, instability of self-image and dissociation. The psychiatric analysis should then turn to whether the identified mental state disturbance related to the diagnosable condition influenced the woman's ability to understand her behaviour, to form a rational judgement or to exercise self-control.

Again, the application of these principles in real cases is far from straightforward. There may be questions about the extent of assessment that is required to confidently make a diagnosis of personality disorder. There is no single approach to assessment, but the psychiatrist needs to ensure that the methodology by which the diagnosis is made (or refuted) is sound with reference to standards of clinical practice and/or the relevant literature. The types of mental state disturbances that a patient with borderline personality disorder may plausibly experience at the time of an aggressive outburst (e.g. intense emotions and alterations in awareness and sense of self) are not uncommon in the accounts of violence by individuals without clinical disorder. This may lead to questions about whether the apparent personality disordered mental state at the time of the killing was or was not related to the personality disorder on this particular occasion. There is no sound psychiatric methodology to address such questions, and as far as psychiatric understanding is concerned the question is not a valid one. The psychiatric expert must stand firm and not extend their opinion beyond the limits of the psychiatric knowledge.

\section{Psychiatric expertise and loss of control}

If the psychiatrist has a role in relation to the defence of loss of control, it is more limited than for diminished responsibility. Section 54(3) of the Coroners and Justice Act (Box 5) appears to prevent the introduction of psychiatric evidence on the presence of a mental disorder where that disorder is relevant only because it causes some impairment in tolerance or self-restraint. The Law Commission suggested that this would mean the jury would be directed that 'alcoholism, for example, or another mental deficiency or disorder that is liable to affect temper or tolerance' should be ignored in relation to a defence of loss of control (Law Commission 2006). However, consideration may be given to whether these factors give grounds for a defence of diminished responsibility. It is suggested that in certain circumstances evidence in relation to psychiatric disorder may be admitted. In the Law Commission report (2006), the example is given of 'low IQ' being accepted as part of the circumstances, if the effect was to misinterpret the provocation as more grave than someone of 'higher intelligence' might have done. With reference to Murphy (1999) and R v Parker [1997], Rix (2011) argues that there are psychiatric disorders that can make a trigger appear more grave or serious than it would appear to a person of similarly normal tolerance and self-restraint but not suffering from the particular disorder.

\section{Conclusions}

Psychiatric experts must combine an advanced level of up-to-date psychiatric knowledge and competencies with an understanding of the legal issues relevant to the questions they are instructed to address. Thus, an expert instructed to provide expert testimony in relation to diminished responsibility or loss of control for homicides on or after 4 October 2010 should be familiar with sections 52 and 54 of the Coroners and Justice Act 2009. As legal not medical concepts, the meanings of diminished responsibility and loss of control will continue to evolve through the process of judicial interpretation.

\section{References}

Archbold JF (2015) Criminal Pleading, Evidence and Practice 2014. Sweet and Maxwell.

Law Commission (2004) Partial Defences to Murder: Final Report (Law Com No 290). TSO (The Stationery Office).

Law Commission (2006) Murder, Manslaughter and Infanticide. Project of the Ninth Programme of Law Reform: Homicide (Law Com No 304). TSO (The Stationery Office)

Law Commission (2011) Expert Evidence in Criminal Proceedings in England and Wales (Law Com No 325). TSO (The Stationery Office).

Mackay (2010) The Coroners and Justice Act 2009 - partial defences to murder (2): the new diminished responsibility plea. Criminal Law Review, 4: $290-302$.

Murphy P (1999) Blackstone's Criminal Practice. Blackstone Press.

Rix KJB (2008) The psychiatrist as expert witness. Part 2: criminal cases and the Royal College of Psychiatrist's guidance. Advances in Psychiatric Treatment, 14: 109-14.

Rix KJB (2011) Expert Psychiatric Evidence. RCPsych Publications.

Thompson L, Cherry J (2014) Mental Health and Scots Law in Practice (2nd Edn). W Green.

\section{Cases and practice directions}

Criminal Practice Directions, Amendment No 2 [2014] EWCA Crim 1569.

Kirkwood v HM Advocate [1939] JC 36.

$R$ v Byrne [1960] 20B 396

$R v$ Golds [2014] EWCA Crim 748.

$R$ v Parker [1997] Crim LR 760

$R$ v Simcox [1964] Crim LR 402.
MCO answers

1 c $\quad 2$ b 3 b 4 e 5 a 


\section{MCQs}

Select the single best option for each question stem

1 The diminished responsibility defence:

a is available to defendants charged with any offence

b is the modern version of the insanity defence

c if accepted, reduces the offence from murder to manslaughter

d if accepted, cannot attract a life sentence

e was introduced into law by the Coroners and Justice Act 2009

2 A psychiatrist acting as an expert witness in cases of diminished responsibility:

a has an overriding duty to provide evidence that supports the instructing party

b should base their opinion on sound methodology and a valid evidence base

c is the arbiter of whether or not the defence of diminished responsibility should succeed

d is required to support the defence of diminished responsibility if there is a verified diagnosis of schizophrenia at the time of the killing e has the responsibility of defining the terms used in sections 52(1) and 53(1) of the Coroners and Justice Act 2009.

3 Within the definition of diminished responsibility introduced by the Coroners and Justice Act 2009:

a the term 'abnormality of mind' is retained

b the phrase 'recognised medical condition' has been introduced

c the abnormality does not have to explain the defendant's act and omissions

$d$ there is reference to a substantial impairment in the ability of the defendant to know the nature and the quality of his actions

e there is a requirement that there must be substantial impairment in the defendant's ability to form a rational judgement.

4 Section 54 of the Coroners and Justice Act 2009 (loss of control):

a amended section 3 of the Homicide Act 1957 (provocation) b legislates that the loss of control must be sudden

c allows for all the 'circumstances' of the defendant to be taken into account when considering whether a hypothetical individual may have reacted in the same way

$\mathrm{d}$ applies if the defendant acted in a considered desire for revenge

e applies if the loss of control was attributable to the defendant's fear of serious violence from the victim.

5 The 'qualifying trigger' for a defence of loss of control:

$\mathrm{a}$ is a requirement for the defence to succeed

b if absent does not negate the defence, if the loss of control was severe

c includes fear of violence only from the victim

d includes things done, but not things said, by another person

e must substantially impair the defendant's ability to exercise self-control if the defence is to succeed. 